\title{
New Labour and New Surveillance: Theoretical and Political Ramifications of C CTV Implementation in the UK
}

\author{
Pete Fussey1
}

\begin{abstract}
This paper examines the implications of New Labour's approaches to crime and disorder on CCTV implementation. It concentrates on the usage of CCTV as one of the government's many initiatives, which are intended to address crime and disorder, including the fear of crime. In particular, the impact of the 1998 Crime and Disorder Act (CDA) - the cornerstone of this government's approach to crime reduction - on the generation of such strategies is examined. The paper revisits neo-Marxist and Foucauldian analyses of the so-called surveillance society through an appraisal of the complex relationship between structure and agency in the formulation and implementation of anti-crime and disorder strategies. Drawing on fieldwork data the paper considers the activities of practitioners at a local level by focusing on the influence of central government, local communities and 'common sense' thinking based on certain criminological theories. It is argued that a myriad of micro-level operations, obligations, processes, managerial concerns (particularly conflict resolution and resource issues), structures and agency - as well as the indirect influence of central government - shape CCTV policy. Ultimately, the creation of new local policy contexts under the CDA emphasise the need to consider incremental and malleable processes concerning the formulation of CCTV policy. In turn, this allows a re-examination of theoretical accounts of surveillance, and their attendant assumptions of sovereign or disciplinary power.
\end{abstract}

\section{Introduction}

This paper discusses research into the implications of New Labour's approaches to crime and disorder on the formulation of CCTV policy in England and Wales. In particular, the impact of the 1998 Crime and Disorder Act (CDA) - the cornerstone of this government's approach to crime reduction - on the generation of crime control strategies involving CCTV is examined. The CDA established a statutory responsibility for local practitioners to form partnerships and devise crime control strategies in their area. As a result, a myriad of local actors, agencies and sections

\footnotetext{
* This paper draws on findings from the author's recently submitted doctoral research entitled 'CCTV in local policy networks: a qualitative study of two community safety partnerships'. I am grateful for the contribution of Chris Crowther (Sheffield Hallam University) in his supervision of the thesis which helped shape many of the ideas expressed in this paper.

${ }^{1}$ School of Law, University of East London, UK. mailto:p.fussey@ uel.ac.uk
} 
of the community became empowered and involved in the creation of local crime reduction strategies, of which CCTV plays a major part. This increased role of local practitioners has led to the inclusion of individual agency and managerial considerations in CCTV policy-making processes. Therefore, despite the central government's traditional involvement in devising policy in this area, new arrangements set up under the CDA demonstrates the importance of what happens at the local level. These features point to political contexts which enable a reexamination of established theorisations of CCTV, such as those forwarded by neo-Marxist and Foucauldian criminologists.

In constructing the argument, this paper adopts the following structure. First, general approaches to crime control under the New Labour administration are discussed and the implications of such developments on CCTV implementation are examined. Following this is a brief analysis of current paradigmatic sociological approaches to understanding CCTV surveillance, discussed in light of these new policy arrangements. This paper will then draw on empirical research conducted into community safety policy networks, involving qualitative interviews with practitioners responsible for CCTV implementation. This data is used to demonstrate how the implementation of CCTV is subject to a range of influences of structure and agency which present a challenge to established sociological theorisations. The paper will conclude with a reevaluation of these perspectives in light of new policy-making sructures and highlight key considerations when theorising public space CCTV in England and Wales.

\section{Approaches to crime and disorder under New Labour.}

The current government's overarching commitments towards crime and disorder reduction is outlined in the government's Crime Reduction Programme, announced in July 1998. This includes two major elements to tackle crime and disorder, namely the Crime Reduction Strategy and the CDA.

\section{The Crime Reduction Strategy}

The main aims of the Crime Reduction Programme are articulated in the Crime Reduction Strategy (CRS). Major elements of the strategy concern 'raising performance' of crime control agencies, implementation of 'best practice', placing additional emphasis on victims of crime, tackling low-level disorder and the reduction of the fear of crime (Home Office, 1998a).

For agencies to raise their performance, the government demands that partnerships must incorporate components of New Public Managerialism (NPM) including the establishment of clear and quantifiable priorities and targets and, in achieving them, develop performance indicators and tangible goals. Connecting with the government's increased emphasis on victims, a major aim of the new strategy is the reduction of high volume crimes affecting the public, specifically burglary and vehicle crime. To reach established targets, attempts are made to base strategies on crime 'hot-spotting' and the 'problem-orientated' approach, target-hardening, a commitment to new technology and a re-evaluation of existing sentencing practice (Home Office, 1998a). 
Together, this approach represents a commitment to rationalist approaches to policy-making. The aim of this approach involves local actors generating objective strategic responses to problems they identify through research and evaluation (see Gladstone, 1980; Laycock and Pease, 1985; Ekblom, 1988). This approach is significant because its proposed selection of local solutions to local problems (Home Office, 1998b) would remove central government from strategic decision-making (such as in the decision to implement CCTV).

Another significant element of the CRS is the government's commitment to tackling anti-social behaviour and disorder. Perceiving it to be a key concern for the public, the government has placed particular emphasis on policing environmental incivilities. Marking a clear adherence to Wilson and Kelling's (1982) 'broken windows' thesis, the government is interested in reducing disorder based on the belief that 'physical and social disorder are distressing in their own right but they are also important because they can lead to more serious crime' (Home Office, 1998a: 22).

Tied in with these specific crime reduction strategies is a commitment to the reduction of fear of crime; an issue long since considered by the central government to be as important as crime itself (Home Office, 1989) and an issue alluded to throughout the general strategy. Signifying a shift in policy-making structures, the Home Office contends that the inclusion of the public in strategic processes enhances the effectiveness of such schemes and particularly assists in fear reduction. Such alteration in policy-making structures also signifies acceptance that traditional agents of crime prevention (the police and government) cannot effectively reduce crime by themselves. Such concern over fear of crime and low-level disorder, is also reflected in the shift in emphasis from the concept of 'crime prevention' to the broader notion of 'community safety'. Though some definitional debate exists, the term 'community safety' contains two elements. First is the concentration on more general issues of 'quality of life' for residents, by reference to a wide range of social issues rather than the narrow concentration on just crime and disorder which is indicative of 'crime prevention'. The second element is the 'concept of community-based action' to tackle crime and disorder (LGMB, 1996, cited in Squires, 1999: 2).

\section{The 1998 Crime and Disorder Act}

Perhaps the most significant piece of legislation affecting CCTV policy contexts is the CDA. In brief, this legislation galvanised many existing informal arrangements and contained the first official and legal obligations for the creation of multi-agency crime control partnerships. Such partnerships incorporated a range of hitherto detached agencies into crime control policy-making processes (Pain et al., 2000). In addition, section 17 of the Act outlined the responsibility of all statutory agencies to consider and take action to prevent any crime and disorder issues possible. As a result, many local actors and agencies were empowered and involved in 'Community Safety Partnerships' consisting of statutory, non-statutory and voluntary agencies.

In apparent reflection of Tony Blair's proclamation (when in opposition) of 'crime as a socialist issue', a key element of these partnerships' strategic processes is the development of policy in consultation with local communities. This is stressed in government guidelines for new partnerships: 
[the] importance of involving the local community at every stage of the process: [it is] clearly right that these people should be invited to participate actively in the process of tackling local problems, not just passively consulted about them (Home Office, 1998b: 5).

The issues highlighted by residents during such consultation exercises should then form the basis of subsequent crime reduction strategies (Ibid.: 12). This auditing process is significant not only because it increases the amount and range of people involved in creating community safety strategies, but also because local strategies become based on perceptions and fear of crime held within local communities. This point is revisited below.

\section{CCTV and the Crime Reduction Programme}

From the government's perspective, CCTV has been long since seen as a useful crime prevention tool with wide ranging uses (Home Office, 1994). Amongst the many uses attributed to CCTV, public order issues are significant. For example, one particular government study highlights how a CCTV scheme in Birmingham incorporates the specific aims of 'deterrence of public disorder, anti-social behaviour and crime' and the 'reduction of general levels of fear of crime within the town (sic) centre' (Brown, 1995: 31). CCTV is therefore considered as an important tool in tackling disorder, anti-social behaviour and the fear of crime, all elements which form a major part of the government's Crime Reduction Programme.

Also in keeping with the main aims of the Crime Reduction Programme, CCTV is seen as important in combating high volume crime, in particular car crime and, to an extent, burglary. Further uses for CCTV include using cameras in order to gather information, such as the police using the cameras to target resources and response, use as a 'capable guardian' and for the identification of suspects (Brown, 1995). Such uses also locate CCTV within situational and traditional administrative approaches to crime prevention. In general, therefore, CCTV is perhaps a unique crime prevention strategy which manages to fulfil the diverse aims set out in the government's Crime Reduction Programme.

Due to these perceived uses, CCTV has become the most important feature of crime reduction strategies, illustrated by the Home Office allocation of $75 \%$ of its crime prevention budget towards CCTV between 1996 and 1998 (NACRO, 2002) and by its domination of local lists of practices (Gilling, 1999). Such is the appeal of CCTV that the Home Office made $£ 153$ million available between 1999 and March 2002 for allocation towards the funding of CCTV schemes (Home Office, 2000b). In response, a vast majority of new CCTV schemes are contingent on securing these funds ${ }^{2}$.

Another feature of the government's approach towards CCTV is the encouragement given to expansion beyond urban centres (which all have CCTV coverage in the UK). For example, the

\footnotetext{
2 The other potentially significant sources of CCTV funding are the Single Regeneration Budget (SRB) and the local council. However, these alternative sources of funding are barely significant when compared to Home Office contributions.
} 
Home Office has announced that at least half of its grants for CCTV implementation will be allocated to schemes in residential areas (Home Office, 2000a, 2000b).

\section{Critical sociological approaches of understanding CCTV surveillance}

Sociological and criminological theory has provided useful ways of understanding the role of CCTV in contemporary society. Speaking heuristically, theorisations based around neo-Marxist and Foucauldian positions have been particularly prevalent. Explanations drawing on neoMarxist frameworks, for instance, stress the use of CCTV to police existing unequal socioeconomic divisions within society and the dominance of particular forms of order based upon materialist agendas. Other criminologists contend that Foucault's (1977) notion of panoptic surveillance underpinning (self) disciplinary society - where power has become ubiquitous, subtle and 'embedded' - is an appropriate template for understanding CCTV in late-modern society. Such paradigmatic conceptualisations of CCTV have been discussed elsewhere (inter alia, Lyon, 1994), and only require brief discussion here before they are re-examined later in the paper.

\section{Neo-Ma rxist perspectives a nd CCTV}

In general, neo-Marxist approaches to CCTV concentrate on two interconnected themes: the use of CCTV to police economically marginalised groups in society and CCTV as a manifestation of sovereign state power.

Much recent work on the operation of CCTV in public space has related to the neo-Marxist theme of policing socio-economic boundaries. This aspect of the neo-Marxist approach refers to CCTV use within the context of the growing influence of economically powerful groups in defining and managing the appropriate use of public space (Graham et al., 1996; Coleman and Sim, 1998). Aware that potential consumers may be deterred from commercial centres by the presence of low-level incivilities such as litter, beggars and gangs of youths; those representing commercial interests seek to remove such 'undesirable' factors from these areas through means such as CCTV surveillance (Davis, 1990, 1992; Beck and Willis, 1995; Reeve, 1996; Bannister et al., 1998; Norris and Armstrong, 1999; Coleman and Sim, 2000; McCahill, 2002). Its ubiquity in urban centres is testament to this. Norris and Armstrong's (1999) ethnographic study into CCTV targeting and operators' conceptualisations of suspicion also situates CCTV in this role.

However, to categorically place these accounts within a neo-Marxist framework is to perhaps oversimplify their conclusions and to overlook the reference to wider debates such as latemodernity, post-Fordist consumerist society, risk and actuarialism inherent in many of these accounts. This paper argues that where neo-Marxist approaches are prevalent and, in light of new CCTV policy contexts, can be challenged is when their conceptualisations of the coercive state are present.

From this perspective, CCTV is viewed as an instrumental technology of the (often) repressive state in a number of ways. Most famous is its conceptualisation in dystopian terms reminiscent of 
Orwell's 'Big Brother'. Mild interpretations of this position can be recognised in the views of civil liberties NGO 'Liberty' who contend that CCTV constitutes an invasion of privacy with 'excessive and unnecessary monitoring of people going about their lawful business' (Liberty, 1996). Although they also stress that, if left unchecked, CCTV may degenerate from a means of crime prevention into a tool of social control(Ibid.).

Neo-Marxist academic commentators maintain that the literature on CCTV and other modes of governance has either ignored or downplayed the significant presence of the 'authoritarian' state (Coleman and Sim, 1998). This argument continues and states that although governance studies give insights into some emerging tendencies in the networks of instrumental discipline, risk management and pervasive surveillance, the power of the UK state has not diminished (Ibid.). More radically, left-wing commentators have alluded to CCTV as a component in the wider 'militarisation of public space' (Davis, 1990, 1992).

However, underpinning this is an assumption of power as a monolithic entity, largely autonomous and operating in a 'top-down' fashion. Power is characterised as embodying a single materialist ideology and (generally) emanating from a central source. This can be conceptualised as 'sovereign power'3. Neo-Marxist conceptualisations of state-sponsored CCTV surveillance, then, necessarily rest on an assumption that a materialistic ideology is being pursued and that it represents the interests of a coercive and monolithic state.

However, the inauguration of the CDA appears to pose problems for such conceptualisations of sovereign power, as contemporary policy-making structures emphasise diversity and devolution over centralised and monolithic transmission of policy. Neo-Marxist criminologists have responded to this changing policy context by arguing that multi-agency crime control may become a potential Trojan Horse' for the government to gain greater control in local areas (Coleman and Sim, 1998). This debate is revisited below in response to empirical data.

Before examining the applicability of these conceptualisations in light of New Labour's approaches to crime reduction, it is necessary to acknowledge the major alternative explanation of CCTV use: the Foucauldian perspective.

\section{Fouca uld ia n perspectives of CCTV}

Foucauldians propose that CCTV is an example of the dispersal of disciplinary mechanisms. In brief, Foucault criticises utopian Enlightenment objectives by arguing that modernity has yielded a form of 'disciplinary' society where power has become ubiquitous, subtle and 'embedded'. Developing via institutions such as schools, factories, prisons and asylums, 'discipline' (once confined to enclosed institutions), is now manifest throughout wider society.

According to Foucault, a system of relentless observation and judgement underpins contemporary forms of discipline. Central to this notion of observation is Bentham's classicist panopticon model where individuals are placed under constant threat of potential surveillance (without knowing if they are actually under surveillance or not) to deter deviant behaviour.

\footnotetext{
3 The term 'sovereign power' is also adopted by Foucault (see later argument).
} 
Foucault notes how these panoptic principles of surveillance are employed throughout society and mark a shift in emphasis from punishing the body (a feature of pre-Enlightenment penal techniques) to regulation of the 'self'.

The initial similarities between this theory and developments in both local governance and the use of CCTV are obvious and striking. Such similarities, especially in the case of CCTV (and its theoretical connection to the 'panopticon'), have not been without comment (amongst others, McCahill, 1998; Norris and Armstrong, 1999) and have also been advocated to varying degrees (Fyfe and Bannister, 1996; Reeve, 1998, Staples, 2000).

However, applications of Foucault's panopticon to explanations of CCTV need to be approached with caution. For example, the use of CCTV to selectively target particular subpopulations (see Norris and Armstrong, 1999), the general application of actuarial techniques against 'the underclass' (Feeley and Simon, 1994), and the increase in exclusionary punishments - such as Anti-Social Behaviour Orders (ASBOs) - suggest that discipline is only 'ubiquitous' for certain groups, rather than for the whole social body as Foucault suggests.

Like neo-Marxist perspectives, Foucauldian accounts harbour assumptions of power which can be re-evaluated in light of recent changes to CCTV policy-making structures. Foucauldian concepts stress dispersed yet interconnected network which applies disciplinary power through (self) coercion. Foucault's position on this subject is outlined with greatest clarity in his 'Governmentality' thesis (Foucault, 1991).

Characteristic of his later work, Foucault (1991) adopts a genealogical approach and traces the relationship between two concepts: sovereign power and what he calls the 'art of government'. Marking a departure from neo-Marxist notions of sovereignty and government as the same thing, Foucault (1991: 94) argues that 'government... can be clearly distinguished from sovereignty'. Moreover, Foucault argues that the central state (sovereignty) has receded and is attributed 'excessive value' (1991: 103). Indeed,

the state, no more probably today than at any other time in its history, does not have this unity, this individuality... this rigorous functionality, nor... this importance... the state is no more than a composite reality and a mythicized abstraction, whose importance is a lot more limited than many of us think. Maybe what is really important for our modernity - that is, for our present - is not so much the éstatisation of society, as the 'governmentalization' of the state (Ibid. emphasis in original).

This suggests that centralised sovereign power has receded and been replaced by dispersed 'government' throughout society. However, Foucault complicates the picture by adding that this does not necessarily mean that sovereignty does not exist at all, rather that remnants of the state are permitted to survive by government. Initially, this characterisation of power may appear justified in light of the recent (apparent) devolution of state management of crime control onto dispersed and localised sites. Moreover, the recent expansion to surveillance into residential 
areas could also provide justification for this more general Foucauldian conceptualisations of surveillance.

This paper now turns towards an examination of empirical data gathered from actors involved with local CCTV policy-making processes. This is undertaken to not only understand the way in which CCTV is implemented, but to also facilitate re-examination of these paradigms and their attendant assumptions of power. This paper argues that such analysis is particularly pertinent in light of the recent legislative changes affecting CCTV policy formulation introduced during New Labour's tenure in government office. Moreover, such paradigmatic theorisations often adopt a 'macro-focus' which generally overlook crucial micro-level processes determining CCTV implementation. Notwithstanding a few important exceptions (for example, Norris and Armstrong, 1999; Coleman and Sim, 2000), much CCTV theorising has avoided a 'grass-roots' focus.

\section{Empinical method}

In light of New Labour's approaches to crime control, it is vital to account for local features to fully understand the implementation of CCTV. In doing so, this paper now draws on data gathered from qualitative interviews with community safety practitioners responsible for the implementation of CCTV. More specifically, key findings from around 40 hours of semistructured interviews conducted with practitioners from two community safety partnerships in England are presented below. These two partnerships represent different demographic areas, one serving a city of in excess of 300000 residents, the other administrating crime reduction strategies in an industrial town of around 100000 inhabitants.

\section{Agency and structure in the CCTV polic y context}

Qualitative analysis of policy networks in local crime control partnerships yielded data demonstrating how the implementation of CCTV is subject to complex influences of both agency and structure. Furthermore, such influences contrast Home Office (and local practitioners') proclamations of rational policy-making. Outlined here is the precise nature of these influences and the manner in which they affect CCTV policy formulation. A common and recurring theme of note throughout this discussion $\dot{s}$ the sustained importance of fear of crime within CCTV policy-making processes. Though its strongest relationship with CCTV is through the application of agency in policy formation, fear of crime also emerges as a crucial issue when considering structural factors, such as new obligations for local consultation and the way this is carried out. Nevertheless, this discussion will begin by examining how the changing policy context has elevated the role of agency, before assessing its exact nature.

\section{Agency in the CCTV polic y-ma king process}

Earlier discussion shows how, as well as restructuring the local delivery of community safety, obligations to form crime control partnerships under the CDA have empowered and incorporated a range of previously lay actors into crime and disorder policy forums (many of which were previously unconnected with crime control), thus increasing the influence of individual agency and preconceived ideas of crime and criminality. 
Despite this, a surprising level of parity exists between extremely diverse agencies concerning key issues. This suggests that in order to make sense of their tasks, newly 'responsibilised' agencies orientate themselves around existing 'common sense' and established, popular wisdom concerning crime control. This similarity is manifestly clear when examining favoured strategies (CCTV) and popular concepts of criminality ('broken windows').

Regarding crime prevention techniques, CCTV is almost unanimously backed throughout both partnerships despite diverse and differing interests between voluntary, public, private and statutory agencies. This demonstrates belief in CCTV as an 'article of faith' (Groombridge and Murji, 1994). Furthermore, practitioners centrally involved in the policy-making process reveal how, reflecting its popularity, CCTV is always requested in public consultation exercises. Newly empowered practitioners perhaps have less reason to be critical within this context. As practitioners themselves have noted, CCTV always becomes the 'starting point in local discussions on crime and disorder' (Interview, 14).

Orientation around axiomatic notions of criminality, particularly the 'broken windows' thesis, is also evident. Given the existence of underpinning assumptions behind the installation of community safety strategies (Crawford, 1998), practitioners' ideas of crime and causation become significant considerations and represent the application of agency. Also pertinent when accounting for the status of 'broken windows' theorising in partnerships is the practice of deviancy amplification (Squires, 1999; Young and Matthews, 2003), the criminalisation of social policy (Stenson, 1998; Rutherford, 2000) and the substitution of 'crime prevention' with broader notions of 'community safety' incorporating semi-criminal 'quality of life' offences. The data also demonstrates how interpretations of 'broken windows' are central to community safety work, accepted fairly uncritically within partnerships and substantially inform subsequent strategic decisions.

Crucially, practitioners consider CCTV to be the most successful remedy for incivilities and also, the most effective use for the cameras. Two interesting points emerge from such perceptions. Firstly, this unites the popular strategy of CCTV with practitioners' commitment to tackling incivilities. Secondly, it constitutes considerable overlap with central government's view of how CCTV should be used (see above and Brown, 1995). The implementation of CCTV to tackle low-level disorder therefore marries a much requested crime control strategy with an issue of major concern for residents. This identification of the prominence of 'broken windows' also, to some extent, supplements research into groups targeted by CCTV (Norris and Armstrong, 1999). The popularity of ideas of 'broken windows' amongst both practitioners and the public suggests reasons why these particular groups may be targeted.

Another (interconnected) expression of agency in the local CCTV policy-making process is the emphasis placed on fear of crime. The data shows how local practitioners consider fear of crime to be a crucial consideration in their decision-making. Furthermore, practitioners connect incivilities with fear, evidenced in their citation of low-level disorder as the most significant contributory factor of fear generation. 
The centrality of fear of crime within partnership decision-making therefore forms the context in which strategies such as CCTV are created and is a crucial factor in understanding its implementation. Direct links between CCTV and fear of crime are also made clear through practitioners' widely held belief that CCTV is one of the most effective fear reducing strategies (also echoing Home Office (1994) sentiments), and constitutes a key role for surveillance systems. In addition to reducing fear through its installation, practitioners believed CCTV installation would lessen fear through a tangible demonstration of partnership commitment towards the community by visibly 'tackling' crime and disorder (see below).

These features point to the importance of community considerations when accounting for the implementation of CCTV. This not only appears to present a challenge to neo-Marxist notions of state-sponsored surveillance, but also, the existence of such agency remains unaccounted for in Foucauldian explanations.

\section{Struc tural influences on the CCTV policy-making process}

Perhaps exerting a clearer impact on the formulation of CCTV policy are 'structural' influences. In this context, 'structure' consists of impositions which hinder the application of objective and rational policy-making. Specifically, this includes micro structural arrangements; issues of coordination, conflict and resolution; conceptual and physical limitations to alternative strategies; partnership obligations such as consultation and ensuring legitimacy; macro agendas; and managerial resource issues. The empirical findings also show how, in addition to local agency, structures surrounding local crime control policy-making generate a climate favourable to the implementation of CCTV.

Contrary to Home Office (1998b) advice, one way this occurs is through partnership stratification. Within current partnership arrangements the police, in particular, attain an elevated status, thus increasing the gravity attached to their views. This is significant as police representatives consistently stressed the importance of situational and enforcement responses to crime and disorder, particularly through the implementation of CCTV. Police dominance in designing and undertaking consultation exercises and their dissemination of information to local partners not only confirms Ericson's (1994) notion of the police as 'knowledge brokers', but also demonstrates their centrality in defining local problems and establishing the focus for crime control policy.

Partnerships are often characterised by conflict. As Crawford (1998) and Phillips (2002) observe, conflict can arise in broad areas such as strategy selection and problem definition. However, more resolute obstacles - often managerial in character - such as cost and individual differences also create discord. Additionally, the lengthy nature of partnership working incorporating already overloaded agencies, the existence of competing performance indicators and waning involvement all add to conflicts. In the pragmatic arena of crime control policymaking, a premium is placed on consensus (Crawford, 1997), tangible outcomes and effective working practices. In this way, disputes are to be avoided and conflict resolution becomes a key function. Here the importance of popular strategies with universal appeal, such as CCTV, cannot be understated in their ability to secure agreement. This mediating course of action suggests local 
crime and disorder policy-making is incremental in character and shows little evidence of a rationalist approach.

This point is further justified by the fact that proposed CCTV implementation does not encounter any significant opposition (from policy-makers) which therefore curtails the lengthy partnership processes and secures agreement amongst practitioners. The main concerns surrounding CCTV subsequently relate to fiscal issues. Moreover, the emphasis placed on partnership working in post-CDA policy-making contexts therefore places greater emphasis upon CCTV as a consensus builder than ever before.

Also significant is the fact that practitioners face substantial obstacles when attempting to implement alternative strategies. In the first instance, situational crime prevention is a favoured approach over other methods of crime reduction. Various factors account for this including the occupational cultures of lead agencies and significant opposition to social crime prevention initiatives (such as NIMBY sentiments) ${ }^{4}$. Other potential strategies for tackling crime and disorder, such as ASBOs along with other judicial and restorative measures, have proved difficult to enforce.

Within the favoured boundaries of situational crime prevention, distinct approaches are in evidence, such as target-hardening, opportunity reduction and increased surveillance (see Crawford, 1997). CCTV is perhaps the only single crime prevention method that satisfies these aims. Furthermore, with little robust evaluation of the effectiveness of strategies, knowledge of what actually works is limited. It is therefore of little surprise that a much hyped tool such as CCTV, which is considered effective in a wide range of contexts, is chosen by practitioners.

One the most significant catalysts for CCTV implementation is public consultation, the centrepiece of local community safety policy-making. As well as constituting the driving force behind many strategies, consultation serves a number of additional purposes. One such role is that by responding to communities, local authorities can claim 'service delivery' and demonstrate both effectiveness and legitimacy (see below). Another important feature of consultation is the emphasis it places on both fear of crime and incivilities. Current methods of community consultation involve asking residents to define local problems and to advocate solutions. This has the effect of bringing residents' fears to the fore and using them as a legitimate foundation on which to base strategies. The identification of local problems is essentially the identification of what particular people feel is the problem. Furthermore, perhaps due to its overt and visible nature, residents almost always identified low-level disorder such as vandalism, graffiti and youths hanging around as a cause for concern. Interviews with the police also indicate recent growing emphasis on low-level disorder simultaneously to increased consultation. In this way, the manner in which policy is generated (with its firm emphasis on consultation) increases the significance of fear of crime and low-level disorder for practitioners.

\footnotetext{
4 The data identified that CCTV implementation is never hindered by lack of support; the main hurdle is securing initial capital resources.
} 
With regard to responsive strategies, this study has shown how current consultation exercises inevitably heighten and legitimise public pressure for CCTV implementation. This is because CCTV is one of the two 'rallying cries' residents request during community safety consultation (the other being increased police presence). This is a particularly significant point when considering the installation of CCTV in areas of higher residential density than urban centres, where the role of public consultation assumes greater importance.

Closely connected with the issue of consultation is the legitimacy it affords partnerships. Primarily, practitioners consider that CCTV demonstrates tangible commitment to communities and fortifies residents' support for the partnership, whilst also reducing their fear. CCTV is popular with the public and practitioners alike and demonstrates that the partnership is 'doing something about crime' and responding to residents' demands. The implementation of dummy cameras in one partnership for this end justifies this point further. For practitioners, therefore, CCTV occupies a symbolic and legitimising role.

Practitioners also stress how local politicians (elected members) favour CCTV for similar reasons. For them, CCTV implementation is hugely symbolic; a 'political tickbox', to quote one Community Safety Officer. Regardless of its suitability and, in spite of any hidden consequences, CCTV sends an incontestable message that local politicians are listening to residents and acting on their concerns. In this way CCTV can be seen as a device for legitimating both local crime control strategies and local democratic processes. In effect, therefore, partnerships will always appear to fulfil their tasks and democratic duty when attempting to install CCTV, regardless of its effectiveness. Such conclusions also add to Coleman and Sim's (2000: 625) claims regarding legitimisation of CCTV through expert discourses. Response to (consulted) resident's demands and the predominance of fear also generate legitimacy for CCTV.

Perhaps the most important structural factors affecting the formulation of CCTV policy are managerial issues. When considering the huge backing potential CCTV implementation enjoys, the main barrier to its installation is in securing capital resources. In addition, other managerial issues - notably time constraints and the imposition of NPM - also affect the surrounding policy process. As mentioned earlier, capital costs for CCTV implementation are disproportionately met by Home Office grants. This has significant ramifications upon neo-Marxist accounts of CCTV and is examined in more depth in the relevant discussion below.

Time constraints also affect the local CCTV policy process. In general, this concerns local practitioners having insufficient time to fulfil the commitments demanded by Home Office funding applications. A consequence of this is inevitable corner-cutting, where the main casualty is public consultation. Ultimately, this results in reliance upon the views of already over-represented groups.

Analysis of day-to-day operation of local policy networks within community safety partnerships therefore reveals a process beset with practical issues and dilemmas, ultimately impacting upon CCTV policy-making. Because CCTV policy-making is mediated through structural factors (amongst other issues), the process by which CCTV is implemented cannot be explained solely in terms of power, despite plausible arguments concerning its targeting and exclusionary function 
once operational. Weaknesses in local policy-making, central government involvement, managerial constraints, conflict and its resolution, the need for consensus and the narrow focus of crime prevention techniques all contribute to local CCTV policy-making and warrant acknowledgement. Also important is the intrinsic connection of fear of crime to these concerns. Furthermore, these factors may constitute a site where challenges to the appropriateness of CCTV installation can be undertaken.

\section{Revisiting Neo-Ma rxist and Foucauldian explanations of C CTV}

As acknowledged earlier, a wide gulf exists between neo-Marxist and Foucauldian theories. What these disparate positions do share, however, is an emphasis on the role of power, although it is also their respective characterisations of such power where they differ most significantly. This distinction is important because it forms the basis of much theoretical analysis of CCTV. This paper now turns towards an examination of how these new policy-contexts reflect on such paradigmatic theorisations.

\section{Re-evaluating Foucauldian concepts of C CTV}

Many recent applications of Foucauldian thought onto the examination of surveillance have drawn on some of Foucault's most absorbing arguments, particularly those concerning the ubiquity of power, the notion of (self) disciplinary power and the 'transportation of penal technique' into open society (Foucault, 1977). Examination of local community safety policy networks also contributes to these debates. For example, a clear commitment to the expansion of surveillance is in evidence, through both informal networks and direct strategies such as neighbourhood wardens, and also through the extension of new sites of CCTV surveillance into the heart of residential communities. Regarding disciplinary power, many 'common-sense' notions of crime control are orientated around situational attempts to stimulate 'self-policing' measures within individuals (see also Jones, 2000). With specific reference to CCTV, practitioners cite its deterrent credentials which - on the surface - also echo such Foucauldian notions of 'self-discipline'.

However, empirical examination lends less support to two further components of Foucauldian concepts of surveillance. First, the notion of the 'seamless integration' of agents and techniques of power and, second, the application of dispersed non-sovereign forms of power. Regarding the former, examination of local policy networks reveals a complex and fragmented administration of crime control policy-making. Contrasting ideas of integrated disciplinary networks forwarded by Foucault and his adherents (for example, Deleuze, 1995), community safety partnerships are far from integrated enterprises. Claims of joined-up working are undermined by difficulties in co-ordinating new and pre-existing plans, constant struggles against conflict, work duplication and waning commitment. Furthermore, the actuality that some microlevel integration is achieved by building consensus around popularist strategies also implies that CCTV is a product of conflict, rather than integrated control.

Concerning the dispersal and disintegration of state power, Foucauldian explanations provide some insight into local network operations and the administering of crime control policy. 
However, its validity only stretches to a certain point. Had local policy been generated in a wholly rational way as practitioners suggest - and in many cases believe - then a strong case for devolved sites of power could have been made through the existence of autonomous policymaking arrangements. Nevertheless, this clearly is not the case, not least due to the impact of structure and agency upon CCTV policy-making. As the following discussion establishes, central government is intrinsically linked with many stages of local CCTV policy-making and counters this central assumption underpinning Foucauldian concepts of surveillance.

A final and related criticism of Foucauldian conceptualisations of CCTV is that the spread of surveillance does not automatically stem from the application of power. Rather, other complicit factors such as the impact of local agency and the importance of fear of crime are crucial to the formulation of CCTV policy. This argument is developed below.

\section{Re-eva lua ting neo-Ma rxist concepts of C CTV}

The analysis of local policy networks also reveals difficulty in applying neo-Marxist conceptualisations of CCTV, though perhaps lends greater support than to Foucauldian accounts. To assess the validity of the neo-Marxist perspective in light of the local formulation of CCTV policy, this paper revisits the two component arguments on which this paradigm is based. The first concerns the use of CCTV for potentially coercive applications against marginalised groups, whilst the second concerns the application of sovereignty.

Regarding the former, the issue of community consent presents a clear challenge to neo-Marxist concepts of CCTV as a repressive tool against economically disadvantaged groups. Indeed, many who request CCTV and are fearful of low-level disorder reside in far from affluent localities and estates. However, closer examination of policy formulation reveals how particular sub-populations, already consistently excluded, are denied articulation within the community safety consultation exercises on which strategies are based. Moreover, present amongst these excluded (or 'hard-to-reach') subpopulations are specific groups - such as youth - who often become the targets for crime and disorder reduction strategies and, as Norris and Armstrong (1999) establish, are the likely subjects of surveillance.

Although the argument that such coercion may result in the exclusion and domination of already disadvantaged and disenfranchised groups is acknowledged, reference needs to be made to fear of crime. The elevated status of fear and the adoption of new policy arrangements emphasising residents' fears and the requirement of tackling incivilities places pressure upon local practitioners to tackle those problems residents perceive and fear. However, these attempts are flawed and, although often well intentioned, the inability of local partnerships to reflexively evaluate categories of risk and deviance (connected to the impact of structure and agency) increases the likelihood that community safety practice falls back on existing prejudices. Some credence is therefore given to neo-Marxist explanations, although their neglect of fear of crime underlines their limits.

The second theme significant in neo-Marxist perspectives regards sovereign power. The complexity of state and local levels of interaction, however, questions sovereign top-down concepts of power. For instance, the CDA places clear emphasis on local activity and the 
empowerment of practitioners at this level. Despite this, analysis of local policy networks also reveals how central government also maintains a high level of control over these processes. This occurs in two major ways.

Most significantly, this is achieved through the control of funding. Initially, local partnerships are not given additional resources to undertake their supplementary community safety tasks. Partnerships then have to seek funding which the Home Office supplies with conditions attached. This indirect, yet comprehensive control of local policy is nowhere more in evidence than in the case of CCTV, where local partnerships overcome prohibitive costs through acquisition of Home Office grants. However, strings are attached, which allows the government to exert its will, set local agendas, define local problems and affect local priorities. Though the criteria are fairly broad, particular encouragement is given to bids for strategies - reflecting the CRS - which focus on issues of 'broken windows' (reduction of low-level disorder including tackling youth and anti-social behaviour), fear reduction and the implementation of CCTV in residential areas (Home Office 2000a, 2000b).

The second manifestation of state influence over local policy-making is more direct; the provision of leads for policy. Here, the Home Office identifies areas for local partnerships to focus on. These may draw attention to areas overlooked by local consultation (such as domestic violence), although attention is demanded on overarching commitments outlined in the CRS, mainly tackling high volume crime and anti-social behaviour. Though these often reflect concerns identified through local audits, potential exists for conflict where the Home Office dictates that emphasis should rest on an issue which is not a problem in a particular locality, particularly in smaller partnerships. However, state intervention in local strategies does not denote complete domination. Rather, as one practitioner stressed, a 'tight/loose set of guidelines' exists (Interview 21). The 'tight' element concerns the theme of action defined by the government, whereas 'loose' refers to the scope given to local practitioners to interpret these leads and devise strategies accordingly. In this sense, local practitioners perform a mediating function between the aims of the state and the application of local policy (see Pahl, 1977; Reiner, 1994 cited in Crowther, 2000: 115). This also underscores the importance of considering the role of agency in community safety policy-making.

In the specific case of CCTV, therefore, the central state retains an influence upon local policy formulation. Along with the lack of cohesion between local agencies, this presents a significant criticism to Foucauldian notions of surveillance. This also posits a challenge to Foucault's (1991) assertion concerning authorisation of partial state survival by dispersed manifestations of power. In the case of community safety partnerships, the opposite appears to be true because ultimate sanction over many policy outputs often rests with the central state, which then 'allows' certain elements of localised government to operate and survive.

This indirect, yet significant, influence of the central state upon CCTV policy-making also lends support to Jessop's (1990) argument that explanations of the demise of state power may be premature. Comment can also be offered on Coleman and Sim's (2000) discussion on this issue. They argue that the state asserts itself locally through a number of ways including dominant definitions of risk. This analysis adds that although the state is indeed active in the formulation of 
local policy, local processes and applications of agency are also complicit in the creation of CCTV policy. Risk categorisations are also generated locally, although they may secure funding for CCTV strategies if they match Home Office definitions. In addition, many local categorisations of risk, once established, are sustained through the failure of local informationgathering techniques and the inability of partnerships to reflexively question them to any significant degree.

Though both neo-Marxist and Foucauldian frameworks have proved useful tools for conceptualising contemporary forms of CCTV surveillance, analysis of local policy networks highlights severe deficiencies in both. However, the sustained influence of the central state does offer a greater degree of affirmation for neo-Marxist concepts of sovereignty than Foucauldian notions of 'governmental' power. Yet both paradigms overlook the importance of the local processes, structures and agency that ultimately shape CCTV policy formulation. Additionally, such local circumstances may help explain why CCTV may be applied in the coercive capacity accented so heavily by these macro-theorisations. Such local issues also generate a context which consistently generates greater demand for - and increased likelihood of - CCTV implementation. Ultimately, in addition to crime control, CCTV fulfils a number of functions which transgress singular issues of power and coercion.

\section{Theorising CCTV implementation}

The question therefore arises of how CCTV can be adequately theorised. However, it is not the intention of this paper to attempt a replacement of partially applicable macro-theorisations with an effort to construct another.

Nevertheless, much of the context for CCTV policy-making can be understood in terms of postCDA policy-making arrangements involving the broader shift towards 'community safety' and its attendant concerns with fear of crime, incivilities and local consultation.

Incorporated within this context are such influential issues as structural and managerial considerations, commitment to servicing local democracy, legitimacy, an overarching dedication to surveillance techniques, belief in the successes of current approaches, and increased intolerance to low-level deviancy, all of which impact upon the formulation of CCTV policy.

Regarding the relationship between central and local government affecting CCTV implementation, the notion of 'government-at-a-distance' (Garland, 1996; Crawford, 1997) appears to hold more weight than the aforementioned paradigmatic theories. Based on this idea, Garland's (1996) concept of responsibilisation appears an apt description of local activity within post-CDA community safety partnerships. Whilst the local agencies are responsibilised and accountable for the delivery of community safety, as Garland (1996: 452) suggests, they are also persuaded to act appropriately by the state. However, this study has shown that, in the specific case of CCTV policy, ensuring compliance from local practitioners involves more robust techniques than mere 'persuasion'. Local agencies are rewarded for toeing the government line on the 'appropriate' problem definition and correct application of CCTV with funding that they would find extremely difficult to secure if they wished to install CCTV in different contexts. More generally, the government also establishes contexts within which local agency may operate. To 
some extent, therefore, this compares favourably with Gamble's (2000, cited in Cope, 2001) view of the state through its enabling capacity; though local practitioners also add an element of further interpretation within this context. Ultimately, the complex relationship between central and local government, relationships with local communities, overarching commitments to fear and incivilities coupled with the influences of agency and structure on CCTV policy development mean that caution needs to be exercised when conceptualising surveillance society in sovereign or disciplinary terms.

\section{References}

Bannister, J., Fyfe, N.R. and Kearns, A. (1998) 'Closed circuit television and the city', in Norris, C., Moran, J. and Armstrong, G. (eds.) Surveillance, Closed Circuit Television and Social Control, Aldershot: Ashgate, 21-41.

Beck, A. and Willis, A. (1995) Crime and Security: Managing the Risk to Safe Shopping, Leicester: Perpetuity Press.

Brown, B. (1995) 'CCTV in Town Centres: Three Case Studies', Police Research Group Crime Detection and Prevention Series Paper No.68. London: HMSO.

Coleman, R., and Sim, J. (1998) 'From the Dockyards to the Disney Store: Surveillance, Risk and Security in Liverpool City Centre', in International Review of Law, Computers and Technology, 12(1):27-45.

Coleman, R. and Sim, J. (2000) 'You'll never walk alone: CCTV surveillance, order and neo-liberal mule in Liverpool city centre', British journal of Sociology, 51(4):623-639.

Cope, S. (2001) 'Analysing Criminal Justice Policy-making: Towards a Policy Networks Approach?', in M. Ryan, S. Savage and D. Wall (eds.) Policy Networks in Criminal Justice, Basingstoke: Palgrave.

Crawford (1997) The Local Governance of Crime: Appeals to Community and Partnerships, Oxford: Clarendon Press.

Crawford, A. (1998) Crime Prevention and Community Safety: Politics, Policies and Practices, London: Longman.

Crowther, C. (2000) Policing Urban Poverty, Basingstoke: Macmillan.

Davis, M. (1990) City of Quartz, London: Pimlico.

Davis, M. (1992) 'Fortress Los Angeles: The Militarization of Urban Space', in Sorkin (ed.) Variation on a Theme Park, New York: Hill and Wang.

Dele uze, G. (1995) 'Postscript on Control Societies', in G. Deleuze Negotiations: 1972-1990, New York: Columbia University Press.

Ekblom, P (1988) Getting the Best out of Crime Analysis, Home Office Crime Prevention Unit Paper 10, London: Home Office.

Ericson, R. (1994) 'The division of expert knowledge in policing and security', British Journal of Sociology, 45(2):149-175.

Feeley, M. and Simon, J. (1994) 'Actuarial Justice: the Emerging New Criminal Law', in Nelkin (ed.) Futures of Criminology, London: Sage. 
Foucault, M. (1977) Discipline and Punish: The Birth of the Prison, London: Penguin.

Foucault, M. (1991) 'Governmentality', in G. Burchill, C. Gordon and P. Miller (eds.) The Foucault Effect: Studies in Governmentality, London, Harvester Wheatsheaf.

Fyfe, N., and Bannister, J. (1996) ‘City Watching: closed circuit television in public spaces’, Area 28(1):37-46.

Garland, D. (1996) 'The Limits of the Sovereign State: strategies of crime control in contemporary society', The British Journal of Criminology, 36(4):445-471.

Gilling, D. (1999) 'Community Safety: a critique', from the British Criminology Conferences: Selected Proceedings, Volume 2.

Gladstone, F.J. (1980) Co-ordinating Crime Prevention Efforts Home Office Research and Planning Unit Publication, London: HMSO.

Graham, S., Brooks, J. and Heery, D. (1996) 'Towns in the Television: Closed circuit TV in British Towns and Cities', Local Government Studies, 22(3):3-27.

Groombridge, N. and Murji, K. (1994) ‘As easy as AB and CCTV?’, Policing, 10(4):283-290.

Home Office (1989) Standing Conference on Crime Prevention, Report of the Working Group on Fear of Crime, 11-12-89, London, HMSO.

Home Office (1994) CCTV: Looking Out for You, London: Home Office.

Home Office (1998a) The Crime Reduction Strategy, London: Home Office.

Home Office (1998b) The Crime and Disorder Act: Guidance on Statutory Crime and Disorder Partnerships, Home Office Communication Directorate, London: Home Office.

Home Office (2000a) The Crime Reduction Programme: Second Round of the CCTV Initiative, http://www.crimereduction.gov.uk/cctvmin.htm

Home Office (2000b) CCTV initiative Application Prospectus, guidance and form for the application of Home Office funding for CCTV schemes, http://www.crimereduction.gov.uk/cctvpros.htm

Jessop, B (1990) State Theory, Cambridge: Polity Press

Jones, R., (2000) 'Digital Rule': Punishment, Control and Technology’, Punishment and Society 2(1):5-21.

Laycock, G. and Pease, K. (1985) 'Crime prevention within the probation service', Probation Journal, 32(2):43-47.

Liberty (1996) 'Video Surveillance in Public Places', Press Release.

Lyon (1994) The Electronic Eye: the Rise of the Surveillance Society, Oxford: Polity.

McCahill, M. (1998) 'Beyond Foucault: towards a contemporary theory of surveillance', in Norris, C., Moran, J. and Armstrong, G. (eds.) (1998) Surveillance, Closed Circuit Television and Social Control, Aldershot.

McCahill, M. (2002) The Surveillance Web: the Rise of Visual Surveillance in an English City, Cullompton: Willan. 
NACRO (2002) To CCTV or not to CCTV: a review of current research into the effectiveness of CCTV systems in reducing crime, Community Safety Practice Briefing, May.

Norris, C., and Armstrong, G. (1999) The Maximum Surveillance Society, Oxford: Berg.

Pahl, R. (1977) 'Managers, Technical Experts and the State', in M. Harloe (ed) Captive Cities, London: John Wiley.

Pain, R., Williams, S. and Hudson, B. (2000) 'Auditing Fear of Crime on North Tyneside: A Qualitative Approach', British Criminology Conference Selected Proceedings, Volume 3.

Phillips, C. (2002) 'From Voluntary to Statutory Status: reflecting on the experience of three partnerships established under the Crime and Disorder Act 1998', in G. Hughes, E. McLaughlin, and J. Muncie (eds.) Crime Prevention and Community Safety, New Directions, London: Sage.

Reeve, A. (1996) 'The Private Realm of the Managed Town Centre', Urban Design International, 1(1):61-80.

Reeve, A. (1998) 'The panopticism of shopping: CCTV and leisure consumption', in C. Norris, J. Moran G. Armstrong (eds.) (1998) Surveillance, Closed Circuit Television and Social Control, Aldershot: Ashgate.

Rutherford, A. (2000) 'An Elephant on the Doorstep: Criminal Policy without Crime in New Labour's Britain', in P. Green and A. Rutherford, Criminal Policy in Transition, Oxford: Hart.

Squires, P. (1999) 'Criminology and the 'Community Safety' Paradigm: Safety, Power and Success and the Limits of the Local', The British Criminology Conferences: Selected Proceedings, Volume 2.

Staples, W. (2000) Everyday Surveillance, Oxford: Rowman \& Littlefield.

Stenson, K. (1998) 'Displacing Social Policy Through Crime Control', in S. Hänninen (ed) 'Displacement of Social Policies', SoPhi: University of Jykväskylä, 117-44.

Wilson, J.Q. and Kelling, G.L. (1982) ‘Broken Windows', Atlantic Monthly, March: 29-38.

Young, J. and Matthews, R. (2003) 'New Labour, crime control and social exclusion', in R. Matthews and J. Young (eds.) The New Politics of Crime and Punishment, Cullompton: Willan. 